\title{
Comparison of In-hospital Outcomes of Percutaneous Coronary Intervention between Young Male and Female Patients with Acute Coronary Syndrome
}

\author{
FATHIMA AAYSHA CADER ${ }^{1}$, AFZALUR RAHMAN ${ }^{2}$, SAHELA NASRIN ${ }^{1}$, M. MAKSUMUL HAQ ${ }^{1}$, \\ MD. RASUL AMIN ${ }^{3}$, MOHAMMAD ARIFUR RAHMAN ${ }^{2}$, MD. SARAWAR ALAM ${ }^{4}$, CHAYAN KUMAR SINGHA ${ }^{3}$, \\ ESHITA BISWAS ${ }^{5}$, MG AZAM ${ }^{2}$ \\ ${ }^{1}$ Department of Cardiology, Ibrahim Cardiac Hospital \& Research Institute (ICHRI), Dhaka, ${ }^{2}$ Department of Cardiology, National \\ Institute of Cardiovascular Diseases (NICVD), Dhaka, ${ }^{3}$ Department of Cardiology, Bangabondhu Sheikh Mujib Medical University \\ (BSMMU), Dhaka, ${ }^{4}$ Consultant, Cardiology, Upazilla Health Complex, Nangalkaot, Comilla, ${ }^{5}$ Department of Medicine, Dhaka \\ National Medical College and Hospital, Dhaka.
}

Address of Correspondence: Dr. Fathima Aaysha Cader, Registrar \& Specialist, Department of Cardiology, Ibrahim Cardiac Hospital \& Research Institute (ICHRI), Email: aaysha.cader@gmail.com.

\begin{abstract}
Background: Acute coronary syndrome (ACS) among young people is increasingly prevalent. However, there is a scarcity of data on the gender differences of in-hospital adverse outcomes among ACS patients after percutaneous coronary intervention (PCI) among young Bangladeshis. This study was conducted to compare the in-hospital outcomes of PCI between young males and females presenting with ACS.

Methods: This prospective observational study was done in the Department of Cardiology, National Institute of Cardiovascular Diseases (NICVD) fromApril 2016 to March 2017. 190 young patients with ACS and undergoing PCI were enrolled. They were equally divided into two groups, group I (young females $<55$ years) and group II (young males $<45$ years).

Results: The mean age of young females and males was $43.8 \pm 6.9$ years and $40.1 \pm 4.3$ years respectively. Young women had significantly higher risk factors of hypertension $(62.1 \%$ vs $33.7 \%, p<0.0010)$ and diabetes $(57.9 \%$ vs $31.6 \%, p<0.001)$ in comparison to young men. Young women had angiographically less severe coronary artery disease (CAD), with significantly higher numbers of ACC/AHA lesion type B2 (40\% vs $25.3 \%, p=0.03)$ and $C(20 \%$ vs $9.47 \%, p=0.03)$, and greater frequency of multivessel disease. Overall, young women experienced greater incidence of in-hospital adverse events in comparison to young men (13.7\% vs. 6.3\%, $p=0.09)$ and had significantly higher rates of severe bleeding (6.3\% vs $1.1 \%, p=0.04)$ and vascular access site complications $(8.4 \%$ vs $2.1 \%, p=0.04)$. Major adverse cardiac events were higher among young females, in comparison to young males $(2.1 \%$ vs $0 \%, p=0.47)$. Young females experienced significantly higher rates of short-term net adverse clinical events (NACE) than young males (10.5\% vs $3.2 \%$, $p=0.04)$. Female gender (odds ratio [OR] 11.7), diabetes (OR 2.5), hypertension (OR 1.78), decreased ejection fraction (OR 1.41) and smaller stent diameter (OR 1.15) were identified as independent predictors of adverse in-hospital outcomes among young ACS patients undergoing PCI.

Conclusion: Young women with ACS presented with significantly more risk factors and experienced more adverse in-hospital outcomes after PCI, despite angiographically less severe CAD. They had significantly greater NACE, largely driven by increased rates of major bleeding. Female gender was an independent predictor of adverse in-hospital outcomes among young ACS patients undergoing PCI.
\end{abstract}

Key words: Acute coronary syndrome, percutaneous coronary intervention, Bangladesh.

\section{Introduction}

Acute coronary syndromes (ACS) are responsible for a large number of emergency hospital admissions and mortality, and represent the principal form of clinical presentation of coronary artery disease (CAD). ACS is increasingly prevalent at a younger age, particularly among those of South Asian ethnicity, in whom a 2-4-fold higher prevalence, increased severity, extreme prematurity and greater mortality has been observed. ${ }^{1}$ The emergence of such an accelerated atherosclerotic process among young adults is of particular concern, as it carries a greater impact both on their lives, as well as a country's economy.

"Young" or premature CAD has been defined in the literature with an age cut-off varying from $\leq 40$ to $\leq 55$ 
years. ${ }^{2-4}$ As cardiovascular disease develops 7 to 10 years later in women than in men, ${ }^{5}$ chiefly owing to the protective effect of endogenous estrogens in young females, the definition of "young" patients in relation to ACS differs for each gender. As such, we defined young females as $<55$ years of age, and young males $<45$ years of age in this study, in accordance with a consensus derived from the literature. . $^{3,46}$

Effective and timely reperfusion of the infarct-related coronary artery is central to optimal treatment for both STEMI and NSTE-ACS and is expeditiously and efficiently achieved by percutaneous coronary intervention (PCI). ${ }^{7}$ The management of MI is not dependent on age, and guideline-suggested therapies are just as applicable to younger patients as they are to older counterparts. ${ }^{2,8,9}$

Although percutaneous revascularization is generally considered to be associated with lower risk and better recovery in young patients, some studies have observed that younger women were more likely than men to experience adverse in-hospital outcomes, including major adverse cardiac events (MACE), peri-procedural complications and especially bleeding, despite similarly high angiographic and procedural success. ${ }^{10-13}$ Alternatively, a few studies have observed higher MACE among young males undergoing PCI. ${ }^{14}$

It has been previously studied in a much older Bangladeshi population, that females undergoing PCI have more adverse in-hospital outcomes in comparison to males, particularly coronary vascular injury and bleeding complications. ${ }^{15}$ However, there are no data on genderrelated differences in thein-hospital outcomes of young ACS patients undergoing PCI in Bangladesh.

The aim of this study is to investigate the in-hospital outcomes of young male and female ACS patients following PCI and to identify the predictors of adverse outcomes in young ACS patients undergoing PCI.

\section{Materials \& Methods}

This prospective observational study was conducted over a period of 1 year from April 2016 to March 2017 at the Department of Cardiology, National Institute of Cardiovascular Diseases (NICVD), Dhaka. Informed written consent was taken from patients or next of kin. Prior ethical approval was obtained from the ethical review committee of NICVD.

Young patients were defined as males $<45$ years and females $<55$ years in consensus with the literature. A total of 190 young patients presenting with ACS, and undergoing PCI during index hospitalisation at NICVD were selected by purposive sampling technique. They were divided into two groups, group I comprised of young females, and group II comprised of young males. Patients with prior MI, mechanical complications, valvular heart disease, cardiomyopathy, prior revascularization, intravenous contrast allergy, serum creatinine $>2 \mathrm{mg} / \mathrm{dl}$ and those with bleeding disorders were excluded.

Patients' demographic and clinical characteristics and ACS typewere recorded. Coronary angiography was performed by conventional method (right femoral access) and evaluated by two experienced cardiologistsfor angiographic variables. Ad hoc PCI to culprit artery was done in case of angiographically significant stenosis and PCI variables were noted.

Patients were followed up for the entire duration of hospital stay and in-hospital outcomes were observed.Overall major adverse cardiac events (MACE) and net adverse clinical events (NACE) were recorded. The definitions of outcome data elements were derived from the 2013 ACCF/AHA Key Data Elements and Definitions for Measuring the Clinical Management and Outcomes of Patients with Acute Coronary Syndromes and Coronary Artery Disease. ${ }^{16}$ MACE was defined as composite of death, MI, stroke or unplanned/ repeat revascularisation (emergency CABG or repeat $\mathrm{PCI}$ ). NACE, a term first introduced in the HORIZONS-AMI trial, ${ }^{17}$ was defined as the combination of major bleeding and a composite of MACE.A composite/ overall adverse in-hospital outcome was recorded as present if the patient experienced any one of the above-mentioned outcome variables.

Data processing and analysis were carried out by using SPSS Version 16.0 (Statistical Package for the Social Sciences by SPSS Inc., Chicago, IL, USA, 2007). Continuous variables were expressed as mean values \pm standard deviation and compared using Student's t-test. Categorical variables were expressed as frequencies with percentages and compared using Chi-square test or Fisher's exact test, as appropriate. Multiple logistic regression analysis was performed to identify predictors of short-term adverse outcomes. A p value of $<0.05$ was considered statistically significant.

\section{Results}

A total of 190 patients were studied, including 95 young females and 95 young males. The overall mean age was $41.3 \pm 5.6$ years (range 18-54 years). The mean age of young females was $43.8 \pm 6.9$ years and young males was $40.1 \pm 4.3$ years. A total of 52.6\% STEMI, 26.3\% NSTEMI and 21.1\% 
UA patients were included with equal distribution between the two genders. Among STEMI patients, 70\% were of anterior and $30 \%$ were of inferior MI.

Table I shows the distribution of risk factors between the groups. Young women showed significantly greater prevalence of hypertension $(62.1 \%$ vs $33.7 \%, \mathrm{p}<0.001)$ and diabetes (57.9\% vs. $31.6 \%$, p, 0.001$)$, while smoking was significantly greater among young males $(70.5 \%$ vs $0 \%, \mathrm{p}<0.001) .70(74 \%)$ of the young women were premenopausal, and among pre-menopausal females, 63\% had history of taking oral contraceptive pill (OCP). Young females had significantly higher EF in comparison to young males $(48.4 \pm 9.3$ vs $45.1 \pm 10.4, \mathrm{p}=0.02)$. The mean percent of left ventricular (LV) ejection fraction (EF) of study patients was $46.8 \pm 10.0$.

Table I

Comparison of risk factors for CAD between young females and males

\begin{tabular}{lccccc}
\hline Risk Factors & \multicolumn{2}{c}{$\begin{array}{c}\text { Young females Young males } \\
(\mathrm{n}, \%)\end{array}$} & $\begin{array}{c}\mathrm{p} \\
(\mathrm{n}, \%)\end{array}$ & value \\
\hline Smoking & 0 & 0.0 & 67 & 70.5 & $<0.001$ \\
Smokeless tobacco & 8 & 8.4 & 3 & 3.2 & 0.21 \\
Hypertension & 59 & 62.1 & 32 & 33.7 & $<0.001$ \\
Diabetes mellitus & 55 & 57.9 & 30 & 31.6 & $<0.001$ \\
Dyslipidaemia & 59 & 62.1 & 50 & 52.6 & 0.18 \\
Family H/O CAD & 41 & 43.2 & 33 & 34.7 & 0.23 \\
\hline
\end{tabular}

Young females demonstrated greater involvement of left main coronary artery (LMCA) $(3.2 \%$ vs. $1.1 \%, p=0.61)$ and left anterior descending (LAD) (51.6\% vs. 45.3\%, $\mathrm{p}=0.38$ ) as culprit artery. Young males demonstrated angiographically more severe CAD, with significantly higher numbers of ACC/AHA lesion type B2 (40\% vs $25.3 \%, p=0.03)$ and $C(20 \%$ vs $9.47 \%, p=0.03)$. Although not statistically significant, young males also had greater frequency of double $(22.1 \%$ vs $18.9 \%, \mathrm{p}=0.13)$ and triple vessel disease $(18.9 \%$ vs $11.6 \%, \mathrm{p}=0.58)$.

Table II details the PCI procedural characteristics between the two groups. Young females had significantly smaller mean stent diameter in comparison to young males ( $2.7 \pm 0.3$ vs. $2.9 \pm 0.4 \mathrm{~mm}, \mathrm{p}=0.02)$, but there was no significant difference in mean stent length between the two groups. Drug eluting stents (DES) were implanted significantly more among young males( $96.8 \%$ vs. $81.1 \%$, $\mathrm{p}=0.001)$. There was no significant difference in terms of angiographic and procedural success between the two groups.

The rates of in-hospital adverse outcomes between the two groups are detailed in table III. Vascular access site complications $(8.4 \%$ vs $2.1 \%, \mathrm{p}=0.04)$ and bleeding ( $13.7 \%$ vs. $4.2 \%, p=0.02)$ were significantly higher among young females. All other in-hospital adverse outcomes were also observed with greater frequency among young females, albeit not statistically significant. There was one in-hospital death from among young females, and none from males.

Table II

Comparison of PCI Procedural characteristics between young females and males

\begin{tabular}{|c|c|c|c|c|c|c|c|c|}
\hline \multirow{2}{*}{$\begin{array}{l}\text { PCI Variables } \\
\text { Stent diameter }(\mathrm{mm}\end{array}$} & \multicolumn{2}{|c|}{$\begin{array}{c}\text { Young females } \\
(\mathrm{n}, \%)\end{array}$} & \multicolumn{2}{|c|}{$\begin{array}{c}\text { Young males } \\
(\mathrm{n}, \%)\end{array}$} & \multicolumn{2}{|c|}{$\begin{array}{l}\text { Total } \\
(\mathrm{n}, \%)\end{array}$} & & \multirow[t]{2}{*}{ p value } \\
\hline & & & & & & & & \\
\hline 2.25 & 12 & 12.6 & 9 & 9.5 & 21 & 11.1 & & 0.48 \\
\hline 2.5 & 32 & 33.7 & 16 & 16.8 & 48 & 25.3 & & 0.007 \\
\hline 2.75 & 15 & 15.8 & 34 & 35.8 & 49 & 25.8 & & 0.002 \\
\hline 3.0 & 30 & 31.6 & 19 & 20.0 & 49 & 25.8 & & 0.06 \\
\hline 3.5 & 6 & 6.3 & 14 & 14.7 & 20 & 10.5 & & 0.04 \\
\hline 4.0 & 0 & 0.0 & 3 & 3.2 & 3 & 1.6 & & 0.08 \\
\hline Mean diameter & \multicolumn{2}{|c|}{$2.7 \pm 0.3$} & \multicolumn{2}{|c|}{$2.9 \pm 0.4$} & \multicolumn{2}{|c|}{$2.8 \pm 0.4$} & & 0.02 \\
\hline \multicolumn{9}{|l|}{ Stent length (mm) } \\
\hline$<20 \mathrm{~mm}$ & 31 & 32.6 & 22 & 23.2 & 63 & 27.9 & & 0.14 \\
\hline$>20 \mathrm{~mm}$ & 64 & 67.4 & 73 & 76.8 & 137 & 72.1 & & \\
\hline Mean \pm SD & \multicolumn{2}{|c|}{$25.0 \pm 9.6$} & \multicolumn{3}{|c|}{$26.6 \pm 9.2$} & \multirow{2}{*}{\multicolumn{2}{|c|}{$25.8 \pm 9.4$}} & 0.26 \\
\hline \multicolumn{7}{|l|}{ Stent type } & & \\
\hline BMS & 18 & 18.9 & 3 & 3.2 & 21 & 11.1 & & 0.001 \\
\hline DES & 77 & 81.1 & 92 & 96.8 & 169 & 88.9 & & \\
\hline \multicolumn{9}{|c|}{ PCI procedural success } \\
\hline Angiographic & 91 & 95.8 & 94 & 98.9 & 185 & 97.4 & & 0.36 \\
\hline Procedural & 90 & 94.7 & 94 & 98.9 & 184 & 96.8 & & 0.21 \\
\hline
\end{tabular}


Table IV shows the comparison of overall in-hospital outcomes between the two groups, which were higher among young females ( $13.7 \%$ vs $6.3 \%, p=0.09$ ). However, it was seen that in-hospital net adverse clinical events (NACE) were significantly higher among young females $(8.4 \%$ vs. $1.1 \%, p=0.04)$, largely driven by their higher rates of GUSTO severe bleeding (6.3\% vs $1.1 \%$, $\mathrm{p}=0.04$ ). Although $2.1 \%$ vs $0 \%$ of MACE was reported for young females vs. young males respectively, this was not statistically significant.
Table $\mathrm{V}$ demonstrates the binary logistic regression analysis of odds ratio (OR) for characteristics of the subjects likely to develop adverse in-hospital outcomes. Female gender, hypertension, diabetes mellitus, decreased $\mathrm{EF}$ and smaller stent diameter were found to be the independently significant predictors of adverse in-hospital outcomes on multi-variate analysis, with odds ratios (OR) being $11.7,1.78,2.5,1.41$ and 1.15 respectively. Age $>40$ years did not emerge as an independent predictor of adverse short-term outcome.

Table-III

Comparison of in-hospital outcomes between young females and males

\begin{tabular}{|c|c|c|c|c|c|}
\hline \multirow{2}{*}{$\begin{array}{l}\text { Outcomes variables } \\
\text { Peri-procedural complications }\end{array}$} & \multicolumn{2}{|c|}{$\begin{array}{c}\text { Young females } \\
(\mathrm{n}, \%)\end{array}$} & \multicolumn{2}{|c|}{$\begin{array}{c}\text { Young males } \\
(\mathrm{n}, \%)\end{array}$} & \multirow{2}{*}{$\begin{array}{c}\mathrm{p} \text { value } \\
0.21\end{array}$} \\
\hline & 8 & 8.4 & 3 & 3.2 & \\
\hline Cardiogenic shock & 6 & 6.3 & 4 & 4.2 & 0.74 \\
\hline Heart failure & 9 & 9.5 & 6 & 6.3 & 0.42 \\
\hline Vascular access site complications & 8 & 8.4 & 2 & 2.1 & 0.04 \\
\hline Bleeding & 13 & 13.7 & 4 & 4.2 & 0.02 \\
\hline Significant arrhythmia & 5 & 5.3 & 3 & 3.2 & 0.47 \\
\hline Stroke & 0 & 0.0 & 0 & 0.0 & - \\
\hline MI & 1 & 1.1 & 0 & 0.0 & 1.00 \\
\hline Stent thrombosis & 1 & 1.1 & 0 & 0.0 & 1.00 \\
\hline Death & 1 & 1.1 & 0 & 0.0 & 1.00 \\
\hline
\end{tabular}

Table-IV

Comparison of composite/ overall adverse outcomes between young females and males

\begin{tabular}{lccccccc}
\hline Outcomes & $\begin{array}{c}\text { Young females } \\
(\mathrm{n}, \%)\end{array}$ & \multicolumn{2}{c}{$\begin{array}{c}\text { Young males } \\
(\mathrm{n}, \%)\end{array}$} & \multicolumn{2}{c}{$\begin{array}{c}\text { Total } \\
(\mathrm{n}, \%)\end{array}$} & $\begin{array}{c}\text { P } \\
\text { value }\end{array}$ \\
\hline Composite/ overall & 13 & 13.7 & 6 & 6.3 & 19 & 10.0 & 0.09 \\
Overall MACE $\dagger$ & 2 & 2.1 & 0 & 0 & 2 & 1.05 & 0.47 \\
Overall NACE $\dagger$ & 8 & 8.4 & 1 & 1.1 & 9 & 4.8 & 0.04 \\
\hline
\end{tabular}

$†$ MACE: Major adverse cardiac event; \$NACE: Net adverse clinical event.

Table-V

Multivariate binary logistic regression analysis for determinants of adverse short-term outcome.

\begin{tabular}{lcc}
\hline Variables of interest & OR $(95 \% \mathrm{CI})$ & P value \\
\hline Smoking & $1.30(0.599-2.210)$ & 0.11 \\
Hypertension & $1.78(1.101-3.694$ & 0.03 \\
Dyslipidemia & $1.29(0.105-3.109)$ & 0.30 \\
Diabetes mellitus & $2.50(1.211-5.321)$ & 0.004 \\
Decreased EF $<55 \%$ & $1.41(1.002-3.420)$ & 0.02 \\
Gensini Score & $1.07(0.201-2.212)$ & 0.55 \\
Smaller stent diameter $<2.5 \mathrm{~mm}$ & $1.15(1.111-3.289)$ & 0.02 \\
Age $>40$ years & $1.03(0.412-1.782)$ & 0.70 \\
Female gender & $11.7(1.72-25.414)$ & 0.02 \\
\hline
\end{tabular}

Dependent variable: short-term adverse outcome

Independent variables: smoking, hypertension, dyslipidemia, diabetes mellitus, decreased EF $<55 \%$, Gensini score, smaller stent diameter $<2.5 \mathrm{~mm}$, age $>40$ years, female gender 


\section{Discussion}

Gender-based differences in outcome after PCI have been a subject of investigation for many years, but the comparison of outcomes among the subset of patients $<55$ years has not been adequately addressed, particularly in the Indian subcontinent.

The mean age of young females was significantly higher than young males $(43.8 \pm 6.9$ vs $40.1 \pm 4.3$ years, $p=0.001)$, which were slightly higher than the patient population of the PROMETHEUS study (48.6 \pm 5.6 years vs. $48.1 \pm 6.0$ years) (10), but is comparable to the age groups of a recent Indian study by Patted, et al. ${ }^{14}$

Young females had significantly worse baseline risk factors than young men, particularly hypertension and diabetes. Several other studies have made similar observations. ${ }^{10,12}$ Diabetes is a particularly strong risk factor for CAD in women,with some studies suggesting that diabetes may negate the protective effects of estrogen on vascular function. ${ }^{18,19}$ Smoking, however, was observed exclusively among young males $(70.5 \%)$, concurring with Indian populations $^{14}$ and some Western studies. ${ }^{11,20}$

Young women had lesser frequency of multivessel disease ( $30.5 \%$ vs $41 \%$ for young females vs males respectively), findings concur with previous outcome-related studies. ${ }^{10,12}$ Prior studies have reported that intracoronary stents have been used less frequently among young women with ACS, although the use of DES has been more frequent among females ${ }^{10}$ or comparable among both genders. ${ }^{21}$ On the contrary, in our study, significantly fewer young females received a DES $(81.1 \%$ vs $96.8 \%, p=0.001)$, possibly explained by the financial constraints, and lesser spending capacity for women in these populations.

There were no significant gender-based differencesin angiographic and procedural success, which concurs with most prior studies wherein adverse outcomes were reported. ${ }^{11,12}$ Despite this, young women had greater incidence of all in-hospital outcome variables studied, particularly bleeding and vascular access site complications. Furthermore, as per GUSTO bleeding classification, significantly more young women had severe bleeding in comparison to young men (6.3\% vs. $1.1 \%)$.

Multiple previous studies have also observed increased bleeding and vascular complications among young women, particularly those undergoing PCI for STEMI. ${ }^{10-13,24}$ Bleeding in patients with ACS is a significant predictor of adverse outcomes, morbidity and mortality. ${ }^{24}$ Patients with STEMI in particular, constitute a high-risk subset of acute patients requiring urgent revascularisation on a background of aggressive pharmacological treatment including intravenous (IV) anticoagulation, IV glycoprotein IIb/IIIa inhibitors, thrombolysis and DAPT. Thus, ACS patients undergoing PCI are more prone to vascular access complications which represent a source of major bleeding sometimes even requiring blood transfusion, especially when the default access route is femoral, where dangerous complications such as retroperitoneal hematoma can arise.

Furthermore, several studies have also found that younger women were more likely than men to experience periprocedural complications such as coronary dissection and abrupt vessel closure, possibly owing to their smaller vessel size leading to difficulty in vessel manipulation and increased susceptibility to mechanical vessel injury. ${ }^{13,25,30}$ In our study, young females showed a nonsignificant increase in such peri-procedural complications. Furthermore, young women had significantly smaller coronary arteries as reflected by the smaller diameter stents implanted in them $(2.7 \pm 0.3$ mm vs. $2.9 \pm 0.4 \mathrm{~mm}$ for females and males respectively). Chandrasekhar, et al. also reported smaller stent diameters $(2.94 \pm 0.5$ vs. $3.1 \pm 0.5 \mathrm{~mm}$ for females and males respectively). ${ }^{10}$ Smaller stent diameter was also a significant predictor of poor outcome on multi-variate logistic regression analysis in this study.

Estrogen, traditionally known to exert a protective effect on vascular endothelial function in pre-menopausal women, may increase the level of various coagulation factors and inflammatory markers and the reaction of vascular endothelium to circulating vasoactive factors, leading to adverse outcomes, ${ }^{26-28}$ and increased susceptibility of some young women to vascular injury. Alternatively, the protective influence of estrogen may be over-ridden by the presence of risk factors, particularly diabetes, resulting in worse outcomes for young women with ACS. ${ }^{13}$

Young females had higher incidence of in hospital MACE in our study $(2.1 \%$ vs $0 \%$ for young women and men respectively), which was not statistically significant $(p=0.47)$. Lansky, et al. ${ }^{11}$ also observed no significant difference in major in-hospital complications constituting MACE ( $3.1 \%$ vs $0.6 \%$ respectively). Neither did Argulian, et al. ${ }^{13}$ who found rates of $4.1 \%$ vs $4.0 \%$ for males and females respectively. Alternatively, Abramson, et al. ${ }^{29}$ and Srinivas, et al. ${ }^{12}$ reported a statistically significant increase of post-PCI in-hospital mortality following acute MI in young females, with female sex found to be an independent predictor of MACE. In contrast to the above studies, Patted, et al. 
reported an insignificant increase in MACE among young Indian male ACS patients. ${ }^{14}$

Consequent to a significantly greater bleeding risk and insignificant increase in MACE, both groups were evaluated for net adverse clinical events (NACE), a term first defined in the HORIZONS-AMI study, and found that women had significantly higher incidence of shortterm NACE ( $8.4 \%$ vs $1.1 \%, p=0.04)$, largely owing to their increased rates of major bleeding.

Female gender was an independent predictor of adverse short-term outcomes in ACS patients, on multivariate logistic regression analysis. Both Srinivas, et al. ${ }^{12}$ and Lansky, et al. ${ }^{11}$ found that female gender was an independent predictor of mortality, vascular complications and MACE.

The presence of greater co-morbidities among females is a contributing factor to their adverse outcomes, as observed by Chandrasekhar, et al. ${ }^{10}$ There are many differences in mechanisms of ACS and plaque characteristics between young males and females that may be attributed to such differences in post-PCI outcome. $^{22}$ These biological differences in atherosclerosis have not been entirely clarified, and further studies using intravascular ultrasound (IVUS) and optical coherence tomography (OCT) may be helpful in defining predictors of gender-based adverse outcome among young patients.

Hypertension and diabetes mellitus also emerged as independent predictors of adverse outcome among young ACS patients undergoing PCI. Young females with ACS are known to present with a greater clustering of these risk factors in comparison to young males, and the presence of such co-morbidities, rather than female gender per se may have been responsible for their increased incidence of adverse in-hospital outcome. Further studies with matching of the number of hypertensive and diabetic patients among the two genders are warranted, to independently test purely for the effect of gender on adverse outcome after PCI.

\section{Limitations}

The study population was relatively smallsingle center study.Sampling method was non-random, so there was risk of selection bias.It was not a single operator study, therefore there may be variation in outcome according to operator expertise.

\section{Conclusion}

This study demonstrated that young women presenting with ACS had clustering of risk factors for CAD and more in-hospital adverse outcomes after PCI than young men, particularly bleeding and vascular complications. Although no statistically significant difference observed for MACE, young women had significantly higher rates of NACE, a composite of MACE and major bleeding. Female gender, diabetes, hypertension, decreased ejection fraction and smaller stent diameter were identified as independent predictors of adverse shortterm outcomes.

Conflict of interest: The authors have no conflicts of interest to declare.

\section{References}

1. Islam AKMM, Majumder AAS. Coronary artery disease in Bangladesh: A review. Indian Heart J. 2013; 65(4): 424-435.

2. Shah N, Kelly AM, Cox N, Wong C, Soon K. Myocardial Infarction in the "Young": Risk Factors, Presentation, Management and Prognosis. Heart Lung Circ. 2016; 25(10):955-960.

3. Mohammad AM, Jehangeer HI, Shaikhow SK. Prevalence and risk factors of premature coronary artery disease in patients undergoing coronary angiography in Kurdistan, Iraq. BMC Cardiovascular Disord. 2015; 15:155.

4. Zuhdi AS, Mariapun J, Hairi NNM, Ahmad WAW, Abidin IZ, Undok AW et al. Young coronary artery disease in patients undergoing percutaneous coronary intervention. Ann Saudi Med. 2013; 33(6):572-78

5. Maas AHEM, Appelman YEA, 2010. Gender differences in coronary heart disease. Neth Heart J. 2010; 18(12): 598-602

6. Al-Murayeh M, Al-Masswary A, Dardir M, Moselhy M, Youssef A.Clinical presentation and short-term outcome of acute coronary syndrome in native young Saudi population. J Saudi Heart Assoc. 2012;24(3):169-175.

7. Bagai A, Dangas GD, Stone GW, Granger CB. Reperfusion strategies in acute coronary syndromes. Circ Res. 2014; 114(12):1918-28.

8. Roffi M, Patrono C, Collet JP, Mueller C, Valgimigli M, Andreotti F, et al. 2015 ESC Guidelines for the Management of Acute Coronary Syndromes in Patients Presenting Without Persistent ST-segment Elevation. Rev EspCardiol (Engl Ed). 2015;68(12):1125.

9. Steg PG, James SK, Atar D,Badano LP, Blömstrom-Lundqvist C, Borger MA, et al. ESC Guidelines for the management of acute myocardial infarction in patients presenting with ST-segment elevation. Eur Heart J. 2012;33(20):2569-619.

10. Chandrasekhar J, Baber U, Sartori S, Faggioni M, Aquino M, Kini A, et al. Sex-related differences in outcomes among men and women under 55 years of age with acute coronary syndrome undergoing percutaneous coronary intervention: Results from the PROMETHEUS study. Catheter Cardiovasc Interv. 2017;89(4): $629-637$

11. Lansky AJ, Mehran R, Dangas G, Cristea E, Shirai K, Costa R,et al. Comparison of differences in outcome after percutaneous coronary intervention in men versus women $<40$ years of age. Am J Cardiol. 2004; 93:916-9

12. Srinivas VS, Garg S, Negassa A, Bang JY, Monrad ES. Persistent sex difference in hospital outcome following percutaneous coronary 
intervention: results from the New York State reporting system. J Invasive Cardiol. 2007; 19:265-268.

13. Argulian E, Patel AD, Abramson JL, Kulkarni A, Champney K, Palmer S, et al. Gender differences in short-term cardiovascular outcomes after percutaneous coronary interventions. Am J Cardiol. 2006; 98:48-53.

14. Patted SV, Porwal SC, Halkati PC,Ambar S, Prasad MR, Metgudmath VB,et al. Comparison of Clinical profile and outcome between young (d"45yrs) male and female patients with coronary artery disease undergoing percutaneous coronary intervention, a single center study. Journal of Medical Science and Clinical Research. 2017; 05(02):17919-17925.

15. Roy US. In-hospital outcome after percutaneous coronary interventions in women and men [MD Cardiology thesis]. Dhaka: University of Dhaka; 2008.

16. Cannon CP, Battler A, Brindis RG, Cox JL, Ellis SG, Every NR,et al. American College of Cardiology key data elements and definitions for measuring the clinical management and outcomes of patients with acute coronary syndromes. A report of the American College of Cardiology Task Force on Clinical Data Standards (Acute Coronary Syndromes Writing Committee). J Am Coll Cardiol. 2001;38(7):2114-30.

17. Stone GW, Witzenbichler B, Guagliumi G,Peruga JZ, Brodie BR, Dudek D, et al. Bivalirudin during primary PCI in acute myocardial infarction. N Engl J Med. 2008;358(21):2218-30.

18. Kawano H, Motoyama T, Ohgushi M, Kugiyama K, Ogawa H, Yasue H. Menstrual cyclic variation of myocardial ischemia in premenopausal women with variant angina. Ann Intern Med. 2001;135(11):.977-981

19. Flaherty JD, Davidson CJ. Diabetes and coronary revascularization. JAMA. 2005;293(12):1501-1508.

20. Vaccarino V, Parsons L, Every NR, Barron HV, Krumholz HM. Sexbased differences in early mortality after myocardial infarction.
National Registry of Myocardial Infarction 2 Participants. N Engl J Med. 1999;341(4):217-25.

21. Epps KC, Holper EM, Selzer F, Vlachos HA, Gualano SK, Abbott JD, et al. Sex Differences in Outcomes Following Percutaneous Coronary Intervention According to Age. Circ Cardiovasc Qual Outcomes. 2016; 9(2 Suppl 1):S16-S25.

22. Chandrasekhar J, Mehran R. Sex-Based Differences in Acute Coronary Syndromes. JACC Cardiovasc Imaging 2016;9(4): $451-464$.

23. Manoukian SV. Predictors and impact of bleeding complications in percutaneous coronary intervention, acute coronary syndromes, and ST-segment elevation myocardial infarction. Am J Cardiol 104: 9C-15C.

24. Lichtman JH, Wang Y, Jones SB, Leifheit-Limson EC, Shaw LJX, Vaccarino V, et al. Age and sex differences in in hospital complication rates and mortality after percutaneous coronary intervention procedures: evidence from the NCDR (®).Am Heart J. 2014;167(3):376-83.

25. Numasawa Y, Kohsaka S, Miyata H, Noma S, Suzuki M, Ishikawa S, et al. Gender Differences in In-Hospital Clinical Outcomes after Percutaneous Coronary Interventions: An Insight from a Japanese Multicenter Registry. PLoS ONE. 2015; 10(1):e0116496.

26. Miller VM, Lewis DA, Barber DA. Gender differences and endothelium-and platelet-derived factors in the coronary circulation. ClinExpPharmacolPhysiol1999; 26:132-136.

27. Rubanyi GM, Johns A, Kauser K. Effect of estrogen on endothelial function and angiogenesis. VascPharmacol2002; 38:89-98.

28. Cushman M. Effects of hormone replacement therapy and estrogen receptor modulators on markers of inflammation and coagulation. Am J Cardiol2002;90(suppl):7F-10F.

29. Abramson JL, Veledar E, Weintraub WS, Vaccarino V. Association between gender and In-Hospital mortality after percutaneous coronary intervention according to age. Am J Cardiol. 2003; 91: 968-71. 